\title{
Translocation of the Helicobacter pylori CagA protein in gastric epithelial cells by a type IV secretion apparatus
}

\author{
Steffen Backert, ${ }^{1}$ Elke Ziska, ${ }^{1}$ Volker Brinkmann, ${ }^{1}$ \\ Ursula Zimny-Arndt, ${ }^{1}$ Alan Fauconnier, ${ }^{2}$ Peter R. \\ Jungblut, ${ }^{1}$ Michael Naumann ${ }^{1}$ and Thomas F. Meyer ${ }^{1 *}$ \\ ${ }^{1}$ Max-Planck-Institut für Infektionsbiologie, Abt. \\ Molekulare Biologie, Monbijoustr. 2, D-10117 Berlin, \\ Germany. ${ }^{2}$ Free University of Brussels, IBMM, Rue des \\ Professeurs Jeener et Brachet 12, B-6041 Gosselies, \\ Belgium.
}

\section{Summary}

Helicobacter pylori is one of the most common bacterial pathogens, infecting about $50 \%$ of the world population. The presence of a pathogenicity island (PAI) in $H$. pylori has been associated with gastric disease. We present evidence that the $H$. pylori protein encoded by the cytotoxin-associated gene $A(\operatorname{cag} A)$ is translocated and phosphorylated in infected epithelial cells. Two-dimensional gel electrophoresis (2-DE) of proteins isolated from infected AGS cells revealed $\boldsymbol{H}$. pylori strain-specific and timedependent tyrosine phosphorylation and dephosphorylation of several 125-135 kDa and 75-80 kDa proteins. Immunoblotting studies, matrix-assisted laser desorption/ionization mass spectrometry (MALDI-MS), cell fractionation and confocal microscopy demonstrated that one of the 125-135 kDa proteins represents the $\boldsymbol{H}$. pylori CagA protein, which is translocated into the host cell membrane and the cytoplasm. Translocation of CagA was dependent on functional cagA gene and virulence (vir) genes of a type IV secretion apparatus composed of virB4, virB7, virB10, virB11 and virD4 encoded in the cag PAl of $\boldsymbol{H}$. pylori. Our findings support the view that $\boldsymbol{H}$. pylori actively translocates virulence determinants, including CagA, which could be involved in the development of a variety of gastric disease.

\section{Introduction}

Helicobacter pylori, a Gram-negative microaerophilic bacterial pathogen and class I carcinogen, is specialized to live for decades in the extreme environment of the

Received 24 January, 2000; accepted 24 January, 2000. *For correspondence. E-mail meyer@mpiib-berlin.mpg.de; Tel. (+49) 30 284604 02; Fax (+49) 3028460401. human stomach. $H$. pylori colonizes and interacts with gastric epithelial cells throughout the host's life and induces gastric inflammation, which can progress to a variety of diseases, such as peptic ulcer, mucosaassociated lymphoma or gastric cancer (Covacci et al., 1999; Cover and Blaser, 1999). The recent determination of two complete $H$. pylori genome sequences of strains 26695 and $\mathrm{J} 99$ provided hints to the presence of several putative virulence factors (Tomb et al., 1997; Alm et al., 1999; Taylor, 1999), those studied in most detail being involved in the production of abundant amounts of urease, the expression of the vacuolating toxin (VacA) or CagA and adhesion to tissue-specific cell receptors (Guruge et al., 1998; Covacci et al., 1999). The major diseaseassociated genetic difference in $H$. pylori isolates is the presence ( $\mathrm{Cag}^{+}$or type I strains) or absence ( $\mathrm{cag}^{-}$or type Il strains) of the cag pathogenicity island (PAI), a locus of about $40 \mathrm{~kb}$ containing up to 31 genes (Censini et al., 1996; Akopyants et al., 1998).

Six of the $H$. pylori cag genes are homologous to the well-known virulence genes virB4, virB7, virB9, virB10, virB11 and virD4 from Agrobacterium tumefaciens, Bordetella pertussis or Legionella pneumophila (Winans et al., 1996; Christie, 1997; Covacci et al., 1999). By analogy of the cag genes to the VirB system of the agrobacterial transfer (T)-DNA-transfer machinery to plant cells, it was suggested recently that the cag PAl might code for an ancient type IV secretion transporter that is capable of exporting a variety of proteinaceous material, and probably also nucleoprotein particles (Censini et al., 1996; Christie, 1997; Backert et al., 1998). In A. tumefaciens, VirB4 exhibits ATPase activity and is tightly associated with the inner cytoplasmic membrane. H. pylori strain 26695 contains altogether four virB4 gene copies. One of them is located inside, but three are outside of the cag PAI. VirB7 is a lipoprotein that, after recruiting VirB9 to form a heterodimer, is postulated to play a role in stabilizing other agrobacterial VirB proteins by the formation of intermolecular disulphide bridges, leading to the assembly of a functional transporter. This heterodimer seems to stabilize VirB10 in higher order complexes. VirB11 is also essential in the assembly of the transporter and exhibits ATPase activity. A ring-shaped structure composed of six monomeric $H$. pylori VirB11 proteins has been observed in vitro (Krause et al., 2000). A potential virB2 gene encoding a pilus-like structure has not been identified yet in $H$. pylori. 


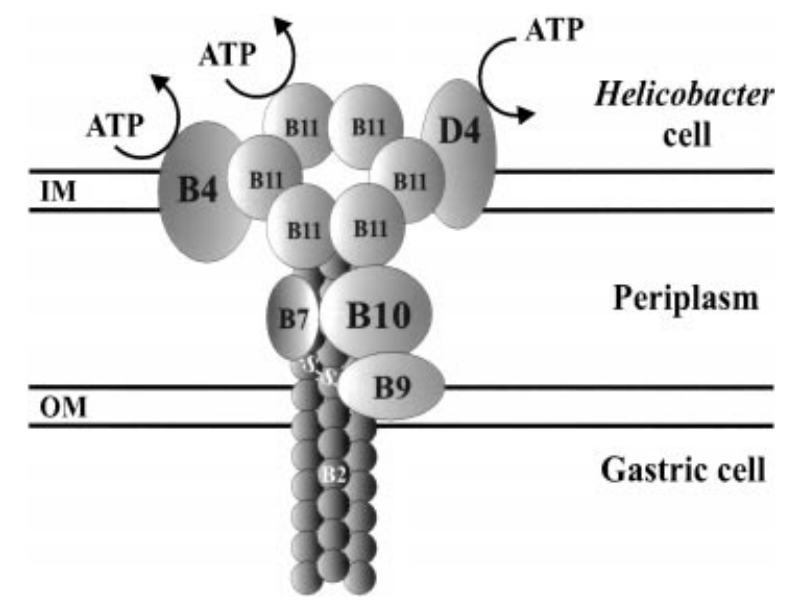

Fig. 1. Hypothetical model of the H. pylori type IV secretion machinery encoded in the cag PAl. The putative position of the core proteins VirB4, VirB7, VirB9, VirB10, VirB11 and VirD4 in the bacterial inner membrane (IM) and outer membrane (OM) is presented by homology with models of the agrobacterial and $B$. pertussis type IV secretion apparatus (Winans et al., 1996; Christie, 1997). The agrobacterial VirB7 and VirB9 proteins form intermolecular heterodimers linked via a disulphide bridge (B7-s-s-B9). Purified H. pylori VirB11 proteins form a hexameric ring in vitro (Krause et al., 2000). Potential ATP-binding domains in the VirB4, VirB11 and VirD4 proteins are indicated as determined from the Prosite database using the HUSAR program (http://www.genius.embnet.dkfz-heidelberg.de). According to this working model, we have produced isogenic knock-out mutants of the respective genes in $H$. pylori strain $\mathrm{P} 1$ to investigate their relevance in the $H$. pylori infection process.

Interestingly, members of the VirD4 protein family that have been suggested to link the T-DNA complex directly to the exporting membrane channel have only been detected in agrobacterial Ti-plasmid and conjugative DNA transfer systems of broad-host-range plasmids but not in protein transporters, such as that of $B$. pertussis (Pansegrau and Lanka, 1996). However, despite the significance of potential virulence genes present, their functional importance as a protein and/or DNA transporter is not known, and the mechanisms by which $H$. pylori causes gastritis, ulcers or cancer remain poorly understood.

It has been demonstrated that $H$. pylori triggers, in a cagdependent manner, cellular events such as the reorganization of the actin cytoskeleton and pedestal formation (Segal et al., 1996), the release of cytokines and the activation of host signalling pathways, leading to the activation of the transcription factors AP-1 and NF-kB (Tummuru et al., 1995; Aihara et al., 1997; Keates et al., 1997; Münzenmaier et al., 1997; Sharma et al., 1998; Li et al., 1999; Naumann et al., 1999). The development of severe gastric disease, which is typically associated with an infection of strains carrying the cag PAl, suggests that the activation of the above-mentioned components of the proinflammatory cellular response is crucial for the clinical outcome.

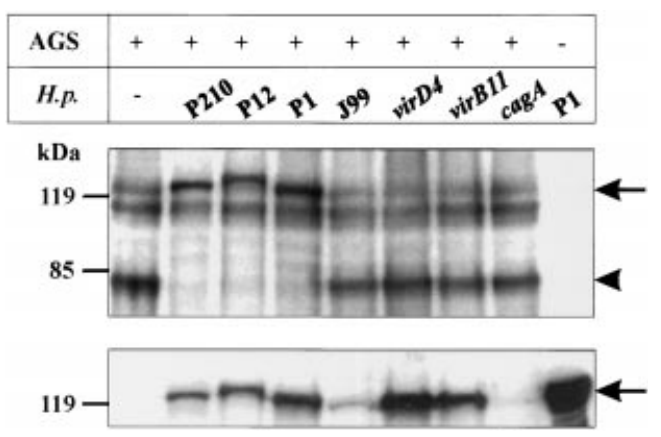

Fig. 2. Phosphorylation of the $H$. pylori CagA protein during infection. Immunoblot analysis of AGS cells infected with $H$. pylori wild-type strains and mutants. Total protein isolated from $H$. pylori strain P1 served as a control. The blot was probed with an antiphosphotyrosine antibody (top) and reprobed with an anti-CagA serum (bottom). Representative results from eight independent experiments are shown. In each experiment, $H$. pylori infection was for $2 \mathrm{~h}$ using a $\mathrm{MOI}$ of 50 . Molecular size markers (in $\mathrm{kDa}$ ) are indicated.

Although recent data described in detail the cellular host response leading to the transcriptional activation of certain target genes (Naumann et al., 1999), no bacterial components directing this signalling have been identified so far. H. pylori was recently shown to induce tyrosine phosphorylation of 105-145 kDa proteins (Segal et al., 1996; 1997; Su et al., 1999), and deconvolution immune fluorescence microscopy suggested that a percentage of bacteria attached to the cell surface is associated with a high concentration of phosphorylated CagA, which could induce cellular changes, such as elongation and spreading of host cells, including the production of filopodia and lamellipodia (Segal et al., 1999).

We are interested in clarifying the role of the type IV secretion apparatus of $H$. pylori in the induction of host signalling responses. Our experimental approach involves the identification of bacterial proteins targeted into the host cell. Data presented here demonstrate that CagA is translocated into the host membrane and into the cytoplasm by the $H$. pylori type IV secretion machinery encoded in the cag PAl. The CagA protein becomes phosphorylated during infection in a strain- and timedependent manner. This process is embedded in a scenario of certain protein tyrosine phosphorylation and dephosphorylation events within the host cell that may be crucial for $H$. pylori virulence.

\section{Results}

Type IV secretion-dependent phosphorylation of the $\mathrm{H}$. pylori CagA protein during infection

In order to understand the molecular mechanisms of the $H$. pylori infection and the potential role of the type IV secretion apparatus encoded in the cag PAl, we have 

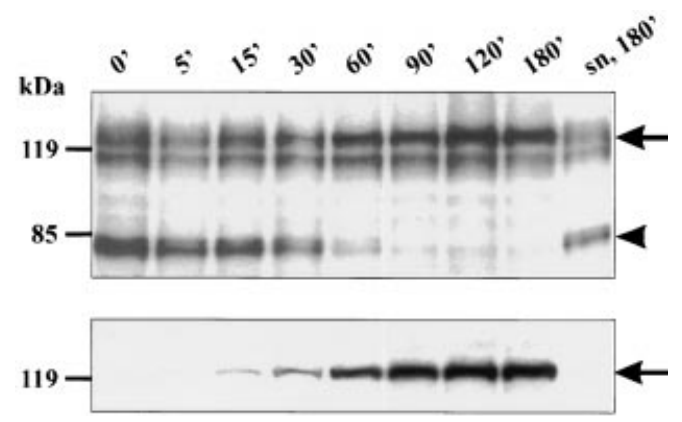

Fig. 3. Time-dependent induction of tyrosine phosphorylation of the CagA protein (see arrow) and dephosphorylation of 75-80 kDa proteins (see arrowhead) in AGS cells upon infection with $H$. pylori wild-type strain P1. As a control, the supernatant (sn) of $H$. pylori strain P1 was added to AGS cells for $180 \mathrm{~min}$. The blot was probed with an antiphosphotyrosine antibody (top) and reprobed with an anti-CagA serum (bottom). Representative results from three independent experiments are shown. A MOI of 50 was used in each experiment. Molecular size markers (in $\mathrm{kDa}$ ) are indicated.

produced a set of vir gene knock-out mutants according to our current working model depicting the putative position of the $H$. pylori Vir proteins assembled as a transporter complex in the bacterial membrane by analogy with the agrobacterial T-DNA secretion machinery (Fig. 1). To study the cellular cross-talk between the pathogen and the host cell, subconfluent monolayers of the human gastric adenocarcinoma cell line AGS were infected with different $H$. pylori strains, followed by analysis of the phosphotyrosine-modified proteins using an anti-phosphotyrosine antibody. Several $H$. pylori type I-wild-type strains, including P1, P12 and P210, induced tyrosine phosphorylation as well as dephosphorylation of 125$135 \mathrm{kDa}$ proteins and dephosphorylation of $75-80 \mathrm{kDa}$ proteins (Fig. 2). Tyrosine phosphorylation and dephosphorylation events have not been detected in the type I strain J99, in the type II strain 1061 lacking the complete cag PAl and in mutants for the core components virB4, virB7, virB10 (data not shown), virB11 and virD4 (Fig. 2, top) of the type IV transporter encoded in the cag PAI. These results were obtained using a multiplicity of

Fig. 4. Phosphorylation patterns of proteins isolated from $\mathrm{H}$. pyloriinfected AGS cells analysed by two-dimensional gel electrophoresis (2-DE). Proteins were prepared from non-infected or AGS cells infected with $H$. pylori $\mathrm{P} 1$ wild-type, virD4 and cagA mutants. A. Silver-stained gel of proteins from non-infected AGS cells. B. Immunoblot analysis with an antiphosphotyrosine antibody. Several proteins were found to be phosphorylated and

dephosphorylated during infection with the $H$. pylori wild-type strain. The white circle indicates a set of two major 100 and $130 \mathrm{kDa}$ phosphorylated protein species. The arrow indicates the position of the CagA protein, as later confirmed with MALDI-MS (see Fig. 5).

The black circle surrounds a group of several dephosphorylated protein species after infection with wild-type $H$. pylori. H. pylori infection was for $2 \mathrm{~h}$ using a $\mathrm{MOI}$ of 50 . Results are representative of three independent experiments.

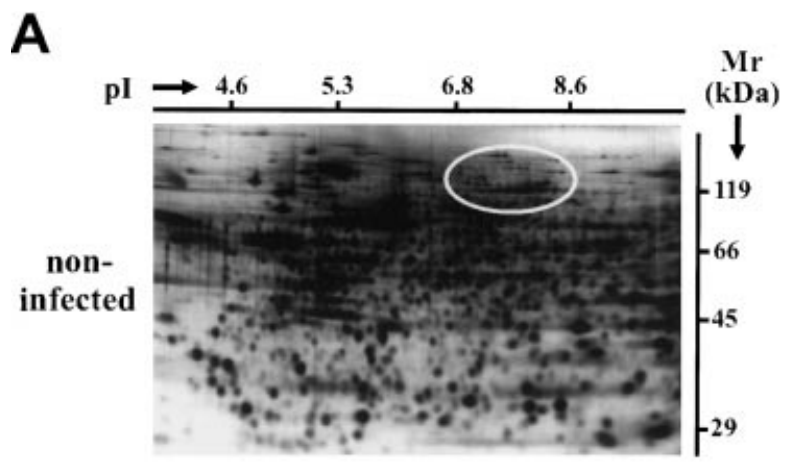

B

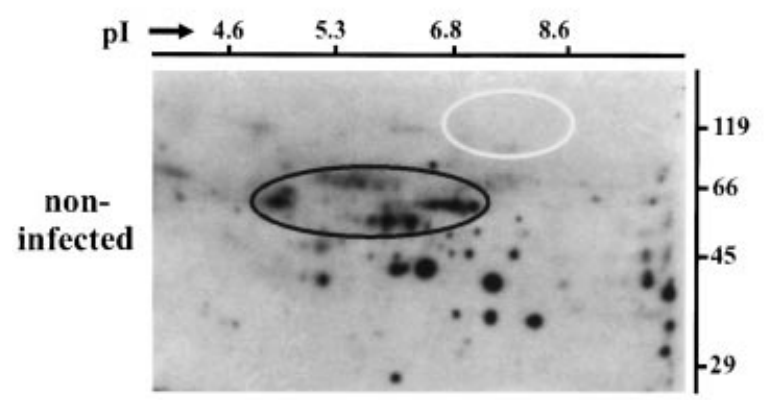

P1

wild-

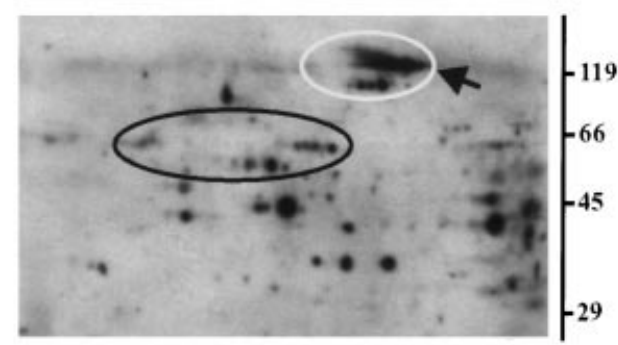

virD4

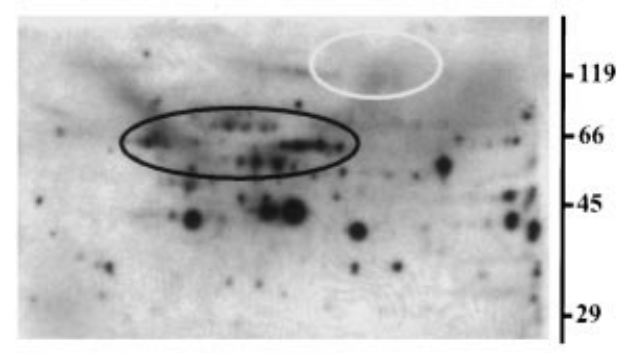

$\operatorname{cag} A$

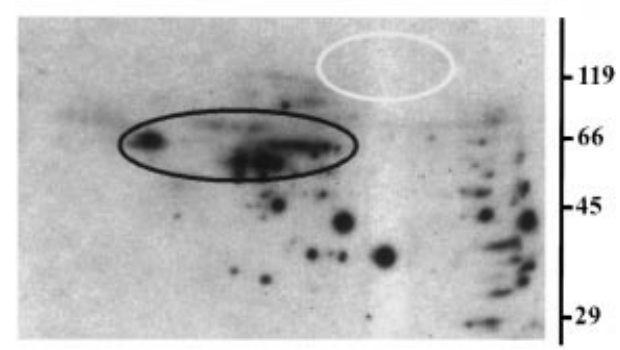


infection (MOI) of 50 for a $2 \mathrm{~h}$ infection and did not change significantly at MOls of 100 or 200 . Molecular weight differences of phosphorylated $125-135 \mathrm{kDa}$ proteins observed in infections with different $H$. pylori wild-type strains suggested that this protein could represent a phosphorylated bacterial protein rather than a host protein. The observation that the isogenic mutant of $\operatorname{cag} A$ abolished the presence of the respective $125 \mathrm{kDa}$ protein and that CagA is not a proposed membrane component of the type IV secretion apparatus (Covacci et al., 1999) led to the assumption that CagA is a bacterial protein translocated in the host cell. Reprobing of the blot with an anti-CagA antibody confirmed that one of the phosphorylated $125-135 \mathrm{kDa}$ proteins represents the CagA protein (Fig. 2, bottom). CagA proteins are also present in attached $H$. pylori of strain $\mathrm{J} 99$ and vir gene mutants, but exclusively in the non-phosphorylated form (Fig. 2, compare top and bottom panels). As a control, $H$. pylori without cell contact does not show phosphorylated CagA, suggesting that host cell contact is a prerequisite for CagA phosphorylation (Fig. 2, top). These observations are consistent with the idea that CagA is phosphorylated only during infections of host cells with $H$. pylori strains encoding functional genes of the proposed type IV secretion machinery. However, we cannot rule out the existence of a polar effect in some of our vir mutants. The motility of some of the mutants was slightly reduced, but none of these mutations significantly affected the ability of the bacterium to adhere to host cells, or the production of the CagA protein (Fig. 2, bottom).

In a time course, phosphorylation of CagA appeared $15 \mathrm{~min}$ after attachment and was strongly established after $1 \mathrm{~h}$ accompanied by a strong dephosphorylation of the $75-80 \mathrm{kDa}$ proteins (Fig. 3, top). Reprobing of this blot with an anti-CagA antibody showed gradually increasing amounts of the CagA protein present during

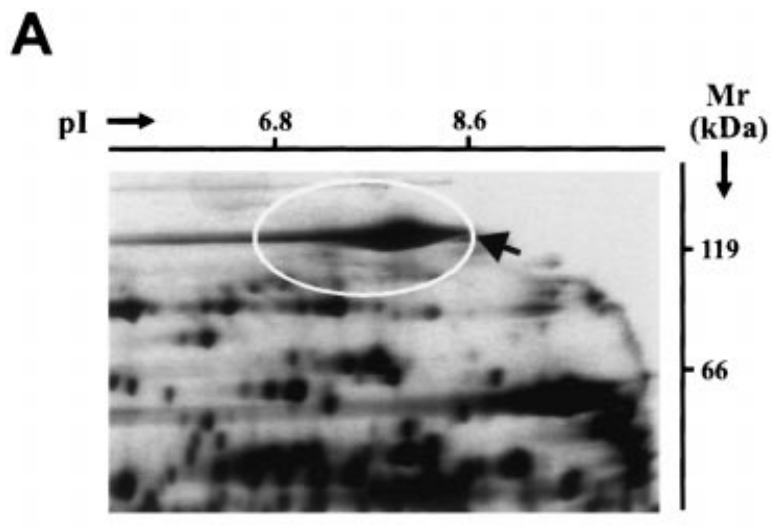

B

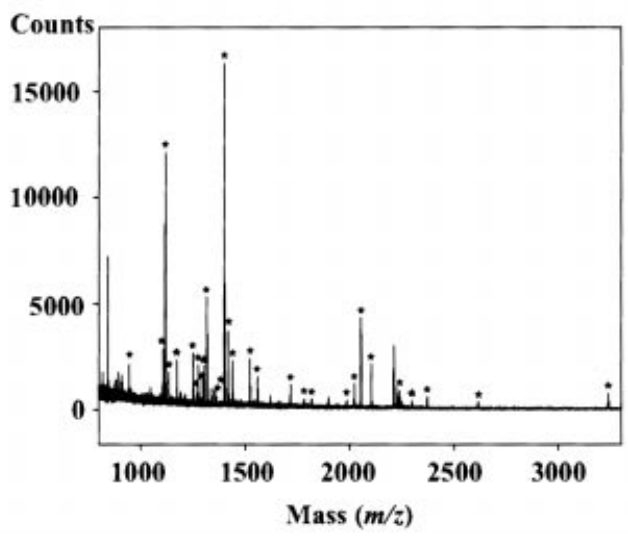

C

MTNETIDQTRTPDQTQSQTAFDPQQFINNLQVAFIKVD NVVASFDPDQKPIVDKNDRDNRQAFDGISQLREEYSNK AIKNPTKKNQYFSDFIDKSNDLINKDNLIDVESSTKSF QKFGDQF Y IFTSWVSHQKDPSKINTRSIRNFMENI IQ PPIPDDKEKAEFLKSAKQSFAGI I IGNQIRTDQKFMGV FDESLKERQEAEKNGGPTGGDWLDIFLSFIFNKKQSSD VKEAINQEPVPHVQPDIATTTTDIQGLPPEARDLLDER GNFSKFTLGDMEMLDVEGVADIDPNYKFNQLLI HNNAI SSVLMGSHNGIEPEKVSLLYAGNGGFGDKHDWNATVGY KDQQGNNVATLINVHMKNGSGLVIAGGEKGINNPSFYI YKEDQLTGSQRALSQEEIRNKVDFMEFLAQNNTKLDNL SEKEKEKFQNEIEDFQKDSKAYLDALGNDRLAFVSKKD TKHSALITEFNNGDLSYTLKOYGKKADKALDREKNVTL QGSLK HDGVMFVDYSNFKYTNASKNPNKGVGATNGVSH LEAGFNKVAVFNLPDLNNLAITSFVRRNLENKLTAKGL SLQEANKLIKDFLSSNKELAGKALNFNKAVAEAKSTGN YDEVKKAQKDLEKSLRKREHLEKEVEKKLESKS GNKNK MEAKAQANSQKDEIFALINKEANRDARAIAYTQNLKGI KRELSDKLEKISKDLKDFSKSFDEFKNGKNKDFSKAEE TLKALKGSVKDLGINPEWI SKVENLNAALNEFRNGKNK DFSKVTQAKSDLENSVKRDI INQKVTDKVDNLNQAVSV AKAMGDFSRVEQVLADLKNFSKEQLAQQAQKNEDFNTG KNSELYQSVKNSVNKTLVGNGLSGIEATALAKNFSDIK KELNEKFKNFNNNNNGLKNSTEPIY YKVNKKKTGQVAS PEEPIYTQVAKKVNAKIDRLNQIASGLGGVGQAAGFPI KRHDKVDDLSKVGLSASPEPIYATIDDLGGPFPLKRHD KVDDLSKVGRSRNQELAQKIDNLNQAVSEAKAGFFGNL EQTIDKLKDSTKKNVMNLYVESAKKVPASLSAKLDNYA INSHTRINSNIQNGAINEKATGMLTQKNPEWLKLVNDK IVAHNVGSVSLSEYDKI GFNQKNMKDYSDSFKFSTKLN NAVKDIKSGFTHFLANAFSTGYYCLARENAEHGIKNVN TKGGFQKS

Fig. 5. Identification of CagA protein by two-dimensional gel electrophoresis (2-DE) and MALDI-MS.

A. Silver-stained gel of proteins from H. pylori strain P1. The arrow indicates the position of the CagA protein, as confirmed with MALDI-MS. B. CagA MALDI-MS. Peaks marked with an asterisk were matched against the H. pylori database and correspond to CagA.

C. Amino acid sequence of the $132.4 \mathrm{kDa}$ CagA protein from H. pylori strain 26695 (ORF 547; Tomb et al., 1997; accession no. P55980). Peptide sequences identified by MALDI-MS after digestion with trypsin are highlighted in black. Overlapping peptide sequences are marked with bars. Two potential tyrosine phosphorylation sites at positions 116-123 and 892-900 have been determined with the Prosite database using the HUSAR program (http://www.genius.embnet.dkfz-heidelberg.de). Tyrosine residues in these motifs are shadowed with a black circle. 


\begin{tabular}{|c|c|c|c|c|c|c|}
\hline H.p. & pl & 개 & $\mathbf{p}^{\prime}$ & $p^{\prime}$ & & (is \\
\hline AGS & - & - & + & + & + & + \\
\hline Fraction & - & - & m & c & m & c \\
\hline
\end{tabular}

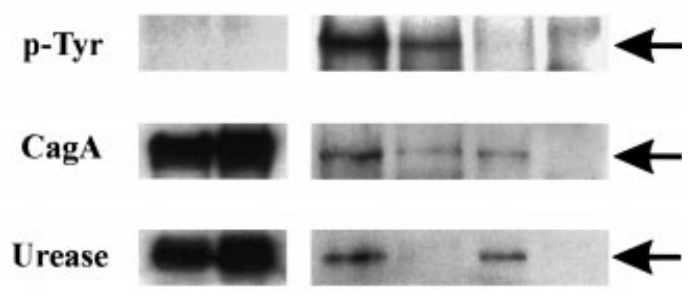

Fig. 6. Translocation of CagA into the host cell. Fractionation of membrane $(\mathrm{m})$ and cytoplasmic (c) proteins after infection of AGS cells with $H$. pylori wild-type strain P1 and the isogenic virB11 mutant was analysed by SDS-PAGE. Identification of the phosphorylated CagA protein with an antiphosphotyrosine antibody (top). Identification of CagA with an anti-CagA serum (middle). The blot shown in the middle was reprobed with an antibody against $H$. pylori urease ( $\beta$-subunit) as a control (bottom). AGS cells were challenged with a $\mathrm{MOI}$ of 100 for $2 \mathrm{~h}$. Total proteins isolated from $H$. pylori strain P1 and the virB11 mutant served as a control. Representative results of three independent experiments are shown.

infection, which is probably the result of an increasing number of attached bacteria and translocated CagA during infection (Fig. 3, bottom). Incubation of AGS cells with the supernatant of the $H$. pylori culture did not induce changes in the tyrosine phosphorylation pattern of proteins, suggesting that CagA is not secreted into the medium.

\section{Identification of CagA by two-dimensional gel electrophoresis and matrix-assisted laser desorption/ ionization mass spectrometry}

To investigate protein tyrosine phosphorylation and dephosphorylation events of infected AGS cells in more detail and to confirm the identification of CagA by matrixassisted laser desorption/ionization mass spectrometry (MALDI-MS) peptide mass fingerprinting, we compared two-dimensional gel electrophoresis (2-DE) phosphotyrosine patterns of non-infected and infected AGS cells after removal of the attached bacteria. Figure $4 \mathrm{~A}$ shows a silver-stained gel of AGS cell proteins to which quantities of protein samples isolated from AGS cells infected with wild-type $H$. pylori strain $\mathrm{P} 1$ or mutants, such as virD4 or $\operatorname{cag} A$, have been standardized. Respective 2-DE blots probed with an anti-phosphotyrosine antibody are shown in Fig. 4B. These blots revealed several significant changes with respect to the phosphorylation status of proteins during host cell infection. In the complete scenario, we detected about six major differences. Most of them were composed of at least four completely or partially dephosphorylated proteins (black circle), and two major 100 and $130 \mathrm{kDa}$ phosphorylated protein species appeared only after infection with wild-type $H$. pylori (white circle).

To identify possible $H$. pylori proteins on these patterns, we compared them with the silver-stained 2-DE protein expression patterns of $H$. pylori wild-type strains P1 (Fig. 5A), 26659, J99 and cagA mutant (data not shown). Overlays of these images revealed one major difference between several wild-type strains and the cag mutant: only the wild-type strains gave rise to a $130 \mathrm{kDa}$ protein (compare Figs $4 \mathrm{~B}$ and $5 \mathrm{~A}$, see arrow). We excised this protein from the Coomassie-stained gel and identified more than 30 peptides (marked with asterisks) by in-gel tryptic digestion followed by MALDI-MS (Fig. 5B). All peptides represented amino acid sequences of the $H$. pylori CagA protein, giving rise to a sequence coverage of $32 \%$. The position of the peptides in the complete CagA protein sequence is shown in Fig. 5C. Two potential tyrosine phosphorylation sites in the CagA sequence are shadowed with a black circle. Our experiments finally demonstrate that one of the $125-135 \mathrm{kDa}$ phosphorylated proteins is indeed CagA. The lack of signals on 2DE blots during infection with the $\mathrm{H}$. pylori vir mutants, such as virD4 (Fig. 4B, white circles), supports the hypothesis that translocation into the host cell is required for phosphorylation of the CagA protein.

\section{Translocation of CagA into the host cell membrane and} cytoplasm

To confirm our hypothesis and to identify the CagA protein within cells, AGS cells were infected with $H$. pylori wildtype strain $\mathrm{P} 1$ and its virB11 mutant for $2 \mathrm{~h}$ followed by the separation of membrane as well as cytoplasmic fractions. The $130 \mathrm{kDa}$ CagA protein was identified by immunoblot analysis with an anti-phosphotyrosine antibody and the anti-CagA antibody (Fig. 6, top). Phosphorylated CagA protein is present in the membrane as well as in the cytoplasm during infection with wild-type $H$. pylori. In contrast, the isogenic virB11 mutant as an important key protein of the type IV secretion apparatus (Fig. 1) did not reveal phosphorylated CagA protein at all. This membrane fraction contained CagA as a result of bacteria attached to the host membrane, but in lower amounts. As a control, CagA protein prepared from $\mathrm{H}$. pylori without host cell contact was not phosphorylated. To verify that the presence of CagA in the host is not a preparation artifact, the blot was reprobed with an antibody against $H$. pylori urease (Fig. 6, bottom). Urease is a protein that is secreted into the medium in high amounts, but is also present in the bacterial cytosol (data not shown). This protein has never been shown to be translocated into host 

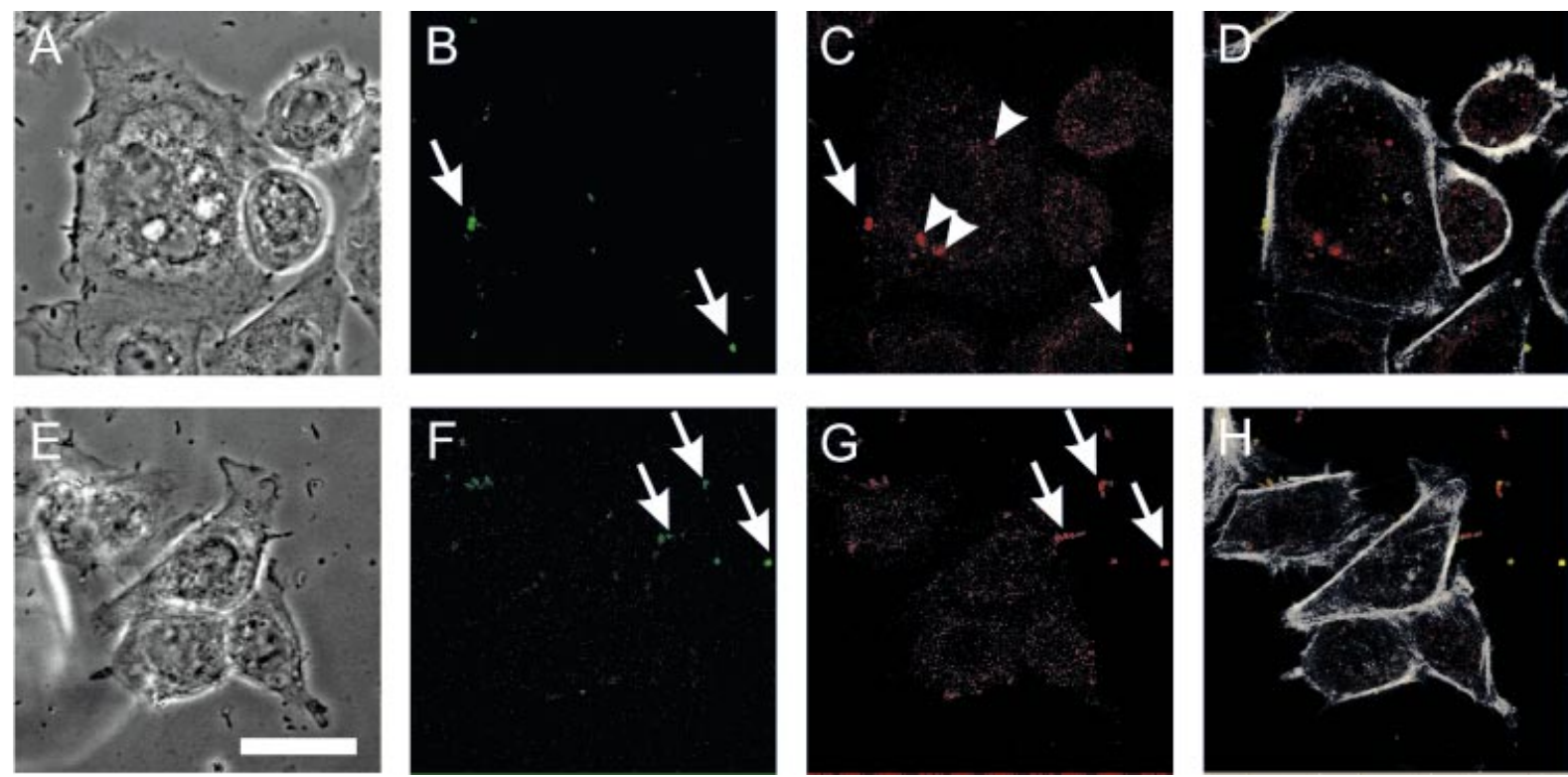

Fig. 7. Identification of CagA in the host membrane and cytoplasm by laser-scanning confocal immune fluorescence microscopy. H. pylori wild type (top, A-D) and virB11 mutant (bottom, E-H) attached to AGS cells were used to localize CagA protein in the host cell.

$A$ and E. Phase-contrast microscopy.

$\mathrm{B}$ and F. Fields stained for H. pylori.

$\mathrm{C}$ and $\mathrm{G}$. Fields stained for CagA.

$\mathrm{D}$ and $\mathrm{H}$. Merged image showing staining for H. pylori (green), CagA (red) and actin (white).

Arrows indicate co-localization of $H$. pylori and CagA (yellow) in the membrane. Arrowheads indicate CagA protein accumulations in the cytoplasm. For better visualization, grey values of confocal images were depicted as pseudocolours. Scale bar $=25 \mu \mathrm{m}$. AGS cells were challenged with a MOI of 100 for $2 \mathrm{~h}$. Results are representative of three independent experiments.

cells. We observed cross-contamination with urease in the membrane because of attached bacteria but no crosscontamination in the host cytosol, suggesting that the presence of CagA protein in the host membrane and cytoplasmic fractions is caused by translocation of the protein from the bacterium into the host.

To visualize CagA protein directly in the host cell and to confirm its translocation from the bacterium into the host membrane and cytoplasm, confocal microscopy was applied. AGS cells were exposed to $H$. pylori wild-type strains and virB4, virB7, virB10, virB11, virD4 and cagA mutant strains. CagA from type I wild-type strains was detected inside or immediately beneath attached bacteria (Fig. 7B-D, arrows) as well as in the cytoplasm of host cells (Fig. 7C and D, arrowheads). Although intracellular $H$. pylori have been observed sporadically, signals of accumulated CagA in the host cytoplasm (as indicated by the arrowheads) did not show co-localization with bacteria. In contrast, CagA from strains mutated in vir genes, as important components of the type IV secretion apparatus, was exclusively located in bacterial cells, suggesting that translocation was blocked or greatly reduced (Fig. 7F and G). Non-infected AGS cells were devoid of the CagA signal, and type II strain 1061 lacking the complete cag PAI or cagA mutant showed no CagA signal, as expected (data not shown).

\section{Discussion}

The delivery of bacterial virulence factors into the host by a type IV secretion apparatus has been well described for the agrobacterial T-DNA and B. pertussis toxin export systems (for reviews, see Winans et al., 1996; Christie, 1997). By comparison, very little is known about the function of the newly discovered type IV secretion systems in Legionella pneumophila (Vogel and Isberg, 1999), Brucella suis (O'Callaghan et al., 1999), Rickettsia prowazekii (Andersson et al., 1998) or Helicobacter pylori (Covacci et al., 1999). The present data provide several lines of evidence for a function of the $H$. pylori type IV secretion machinery in actively translocating an important virulence determinant, CagA, into the host cell. Although no function for this immune-dominant antigen has been reported so far, we made the following observations that may deepen our understanding of the function of the $H$. pylori virulence system. (i) The CagA protein is tyrosine phosphorylated during infection with cultured gastric cells in a strain- and time-dependent manner. The CagA protein is not tyrosine phosphorylated in the $H$. pylori cells without host cell contact. Only several type I, but no type II, wild-type strains were able to induce CagA phosphorylation. (ii) CagA was not secreted into the medium, as supported by the observation that supernatants of $H$.

(c) 2000 Blackwell Science Ltd, Cellular Microbiology, 2, 155-164 
pylori type I strains did not induce changes in the phosphotyrosine pattern of infected AGS cells. (iii) We have shown the insertion of CagA into the membrane (at positions at which $H$. pylori is attached) and the cytosol of the host by two independent experimental approaches including fractionation studies and confocal microscopy. (iv) Injection and tyrosine phosphorylation of CagA in the host cell appears to be dependent on important functional core components (vir genes) and the cagA gene of the $H$. pylori type IV secretion apparatus encoded by the cag PAI (compare Fig. 1). (v) Translocation and phosphorylation of the CagA protein is accompanied by additional tyrosine phosphorylation and dephosphorylation events of several proteins in the host.

To facilitate studies of the $H$. pylori-induced signalling processes that underlie cag-dependent mechanisms, we have produced a set of cag mutants. The cag mutants were from strain P1, a type I strain that actually encodes all the putative homologues of the agrobacterial virB4, virB7, virB9, virB10, virB11 and virD4 genes reported so far (Covacci et al., 1999), and provokes a very strong host response. We have produced mutants from all these genes, except the virB9 gene; although present in P1, we were not yet able to produce a functional mutant. However, all the open reading frames (ORFs) tested were needed for successful translocation and phosphorylation of the $H$. pylori CagA protein. Although we cannot completely rule out the occurrence of polar effects on downstream genes as a result of the integrated $\mathrm{Cm}^{\mathrm{R}}$ cassette in some of these mutants, the protein expression patterns and the patterns of tyrosine-phosphorylated proteins of infected AGS cells in 2-DE were consistently observed with different MOls similar to that produced by type II strains lacking the complete cag PAI. Moreover, our vir mutants were not significantly reduced in their ability to attach to the host cell when compared with its wild type, and also did not significantly affect the expression level of the CagA protein. However, our results, i.e. (i) the inability of the $H$. pylori vir gene mutant strains to translocate and phosphorylate the CagA protein, and (ii) the homology of these vir genes to that of $A$. tumefaciens or $B$. pertussis, are collectively consistent with a model in which different proteins encoded in the cag PAI form a contact-dependent and type IV-like secretion apparatus responsible for direct injection of CagA into the host cell (Fig. 1). Our results led us to suggest that intact virB4, virB7, virB10, virB11, virD4, cagA and possibly also virB9 gene products are essential in the injection process of CagA.

Our data considerably extend those of Segal et al. (1999), who first presented evidence of CagA phosphorylation during the infection process. These authors showed that CagA is necessary to induce a growth factor-like phenotype (hummingbird) in host gastric cells and another
CagA-independent cellular phenotype called SFA (stress fibre associated). We have also identified phosphorylated CagA protein by several approaches, including MALDIMS. In addition, searches in the Prosite database revealed two potential tyrosine phosphorylation sites in the CagA sequence of strain 26695. In another strain, J99, CagA is also present during infection, but not in the phosphorylated form. Alignments of CagA protein sequences from strains $\mathrm{J} 99$ and 26695 revealed that CagA of $\mathrm{J} 99$ is mutated in respective tyrosine residues, which supports the view that both sites detected in strain 26695 could indeed have a function in vivo (unpublished data). This conclusion is supported by our observation that, only in infections with $H$. pylori type I strains showing phosphorylated CagA protein, were dephosphorylated 75-80 kDa proteins additionally observed in a timedependent manner. The potential role of these tyrosine phosphorylation sites in the infection process and possibly in gastric disease has to be elucidated in future studies.

The potential function of the translocated CagA protein in the host is unknown. Database searches of CagA sequences did not reveal significant homologies to any known proteins. Recent mutational studies have implicated several genes in the cag PAl in the induction of interleukin (IL)-8 but some, most strikingly cagA, were not involved (Tummuru et al., 1995; Censini et al., 1996; Li et al., 1999). By analogy with the enteropathogenic Escherichia coli Tir protein, which is secreted in the host membrane by the bacterial type III secretion machinery and subsequently tyrosine phosphorylated, thereafter acting as a receptor for intimin binding on the bacterial surface (Kenny et al., 1997), it is tempting to speculate that CagA could act as a receptor for $H$. pylori in a similar manner to attract additional bacteria to adhere. Alternatively, other unknown function(s) should also be considered, as CagA has also been detected in the host cytoplasm. As outlined above, translocation and tyrosine phosphorylation of CagA are temporally correlated with dephosphorylation of $75-80 \mathrm{kDa}$ proteins. The nature and function of these host proteins is unknown as yet. It will be very interesting in future to study the correlation between the two events, which may shed new light on $H$. pylori-induced signalling processes in gastric disease.

In conclusion, our study has revealed that CagA is the first $H$. pylori protein shown to be translocated into the host. The present in vitro studies emphasize the importance of several agrobacterial vir gene homologues in the translocation and tyrosine phosphorylation of the $H$. pylori CagA protein, possibly by an active process via a type IV secretion apparatus encoded in the cag PAI. This event is temporally embedded in a scenario of additional protein tyrosine phosphorylation and dephosphorylation events within the host cell, which may be crucial for $H$. pylori virulence. We feel that further molecular dissection 
of the cag PAI, as well as CagA translocation and tyrosine phosphorylation-dependent signalling processes, will significantly contribute to an understanding of $H$. pylori pathogenesis mechanisms.

\section{Experimental procedures}

\section{Bacterial strains and mutagenesis}

Type I H. pylori strains P1, P12 and P92 (Sydney strain SS1) are clinical isolates that have been described previously (Schmitt and Haas, 1994; Corthesy-Theulaz et al., 1996; Lee et al., 1997). H. pylori strain P210 is a clinical strain isolated from a patient with gastric cancer. The type II $H$. pylori strain 1061 was kindly provided by J. Bijlsma and H. Kusters (Department of Medical Microbiology, Vrije Universiteit Amsterdam, The Netherlands). Strains 26695 and J99 are $H$. pylori isolates obtained from TIGR and AstraZeneca respectively (Tomb et al., 1997; Alm et al., 1999). Isogenic P1 knock-out mutants have been constructed by insertion of a chloramphenicol resistance gene cassette $\left(\mathrm{Cm}^{\mathrm{R}}, 1 \mathrm{~kb}\right.$ $B a m H I / B g l l$ fragment of plasmid pTnMax1) in cloned virB4 (P205), virB7 (P206), virB10 (P207), virB11 (P208), virD4 (P209) and $\operatorname{cagA}$ (P211) genes according to a standard protocol (Haas et al., 1993). Briefly, the genes of interest were amplified by polymerase chain reaction (PCR) using primers based on the sequences of the genes from strains 26695 and $\mathrm{J} 99$ in the AstraZeneca H. pylori genome database (http://www.astra-boston.com/hpylori/). The PCR products were cloned in the PGEM-T vector (Promega). After mutagenesis by insertion of the $\mathrm{Cm}^{\mathrm{R}}$ cassette in the vir genes, $3-5 \mu \mathrm{g}$ of supercoiled plasmid DNA was added to $1 \times 10^{8}$ bacteria $\mathrm{ml}^{-1}$ brain-heart infusion $(\mathrm{BHI})$ medium. After incubation for $6 \mathrm{~h}$, bacteria were grown on agar plates containing 4-6 $\mathrm{mg} \mathrm{ml}^{-1}$ chloramphenicol to select for chloramphenicol-resistant transformants obtained after 4-5 days according to a standard procedure (Haas et al., 1993). Correct integration of the $\mathrm{Cm}^{\mathrm{R}}$ cassette into the $H$. pylori chromosome by double cross-over recombination was confirmed by PCR. All $H$. pylori strains were grown on horse serum agar plates supplemented with vancomycin $\left(10 \mu \mathrm{g} \mathrm{ml}^{-1}\right)$, nystatin $\left(1 \mu \mathrm{g} \mathrm{ml}^{-1}\right)$ and trimethoprim $\left(5 \mu \mathrm{g} \mathrm{ml}^{-1}\right)$ and, if necessary, with chloramphenicol (4$6 \mu \mathrm{g} \mathrm{ml}^{-1}$ ). Incubation was at $37^{\circ} \mathrm{C}$ for 2 days in an anaerobic jar containing a gas mix of $5 \% \mathrm{O}_{2}, 10 \% \mathrm{CO}_{2}$ and $85 \% \mathrm{~N}_{2}$ (Oxoid).

\section{Infection assays and immunoblot analysis}

AGS cells (ATCC CRL 1739; a human gastric adenocarcinoma epithelial cell line) were grown in $25 \mathrm{~cm}^{2}$ flasks with RPMI $/ 10 \%$ FCS for 1 or 2 days respectively. The cells were washed once with PBS, and $4 \mathrm{ml}$ of fresh medium was added to each flask. $H$. pylori $\left(1 \times 10^{8}\right)$ were resuspended in $0.5 \mathrm{ml}$ of PBS and added to $2 \times 10^{6}$ AGS cells at a MOI of 50 . $H$. pylori culture supernatant was obtained after completely pelleting bacteria at $3000 \mathrm{~g}$ for $10 \mathrm{~min}$. After incubation in a $5 \% \mathrm{CO}_{2} / 95 \%$ air incubator for $1-3 \mathrm{~h}$, AGS cells were washed once with PBS (containing $1 \mathrm{mM}$ sodium vanadate) to remove non-adherent bacteria. Whole-cell lysates with attached bacteria were made by pelleting the cells at $600 \mathrm{~g}$ and resuspending the pellet in an equal amount of $2 \times$ SDS lysis buffer (250 mM Tris- $\mathrm{HCl}, \mathrm{pH} 8.0,4 \%$ SDS, 20\% glycerol, $0.002 \%$ bromophenol blue, $6 \% 2$-mercaptoethanol). SDS-PAGE and electroblotting to Immobilon-P membranes were performed as described by the manufacturers (Millipore, Bio-Rad). Antibody binding and detection were performed with the ECL system (Amersham). Mouse monoclonal antiphosphotyrosine antibody PY99 was purchased from Santa Cruz Biotechnology. Polyclonal antiurease antibodies have been described recently (Gomez-Duarte et al., 1998). Polyclonal anti-CagA antibodies were produced by immunization of mice with a fusion protein containing a CagA polypeptide that corresponds to residues 110-769 of the CagA sequence reported recently (Tummuru et al., 1993).

\section{Cellular fractionation}

For the preparation of membrane/nuclear and cytoplasmic fractions of infected host cells, we followed a special protocol to remove adherent and non-adherent bacteria. For this purpose, $2 \times 10^{6}$ infected cells were washed with PBS (containing $1 \mathrm{mM}$ sodium vanadate) to remove non-adherent bacteria. Adherent bacteria were detached from AGS cells by incubation with $2 \mathrm{ml}$ of trypsin for $5 \mathrm{~min}$. The following steps were carried out at $4^{\circ} \mathrm{C}$ with precooled solutions. PBS/10\% FCS ( $4 \mathrm{ml}$ ) was added to the cells, followed by centrifugation at $600 \times g$ for $5 \mathrm{~min}$. The majority of the remaining bacteria was removed by several washing steps in PBS. The pellets with purified AGS cells were washed again in $1 \mathrm{ml}$ of buffer [10 mM Tris- $\mathrm{HCl}, \mathrm{pH} 7.9,10 \mathrm{mM} \mathrm{KCl}, 1.5 \mathrm{mM} \mathrm{MgCl} 2,10 \%$ glycerol, $10 \mathrm{mM} \mathrm{K}_{2} \mathrm{HPO}_{4}, 1 \mathrm{mM}$ sodium vanadate, $10 \mathrm{mM}$ $\mathrm{NaF}, 0.5 \mathrm{mM}$ dithiothreitol (DTT) and $0.5 \mathrm{mM}$ phenylmethylsulphonyl fluoride (PMSF)]. The cells were centrifuged again at $600 \times g$ for $5 \mathrm{~min}$, and the pellet was resuspended in $200 \mu \mathrm{l}$ of buffer. Nonidet-P40 (2 $\mu \mathrm{l})$ was added to the cells, gently mixed and incubated for $1 \mathrm{~min}$ on ice. Membrane/ nuclear fractions were collected by pelleting at $1000 \mathrm{~g}$ for $10 \mathrm{~min}$. Cytoplasmic fractions were purified from the remaining cell debris by centrifugation at $12000 \mathrm{~g}$ for $30 \mathrm{~min}$. The fractions were resuspended in an equal amount of $2 \times$ SDS lysis buffer.

\section{Two-dimensional electrophoresis (2-DE)}

For the resolution of proteins isolated from infected AGS cells by $2-\mathrm{DE}$, we followed the protocol described above and removed adherent and non-adherent bacteria. The purified AGS cells were washed again with PBS and sonicated in the presence of proteinase and phosphatase inhibitors $(0.5 \mathrm{mM}$ PMSF, $2 \mu \mathrm{g} \mathrm{ml}^{-1}$ aprotinin, $2 \mu \mathrm{g} \mathrm{m}^{-1}$ leupeptin and $1 \mathrm{mM}$ sodium vanadate). Proteins from $H$. pylori strains $\mathrm{P} 1, \mathrm{~J} 99$ and 26695 were isolated from bacterial pellets obtained after centrifugation at $2000 \mathrm{~g}$. All protein fractions were treated with $9 \mathrm{M}$ urea, $70 \mathrm{mM}$ DTT and $2 \%$ Triton X-100 to obtain completely denatured and reduced proteins. For the resolution of proteins, we applied a 2-DE gel system (Jungblut and Seifert, 1990) in a $7 \mathrm{~cm} \times 8 \mathrm{~cm}$ version. Protein $(50 \mu \mathrm{g})$ was loaded to the anodic side of the isoelectric focusing (IEF) gel. The proteins were detected by silver staining (Jungblut and 
Seifert, 1990), by staining with Coomassie brilliant blue R250 and by immunoblot analysis as described above.

\section{Peptide mass spectrometry}

For the identification of CagA protein, $300 \mu \mathrm{g}$ of total protein extract was applied to large-scale 2-DE gel $(20 \mathrm{~cm} \times 30 \mathrm{~cm})$ with a resolution power of about 5000 protein species. Respective spots were excised from the gel and subjected to in-gel tryptic digestion using a peptide-collecting device (Otto et al., 1996). The peptide solution was mixed with an equal volume of a saturated $\alpha$-cyano-4-hydroxy cinnamic acid solution in $50 \%$ acetonitrile, $0.3 \%$ TFA, and $2 \mu \mathrm{l}$ was applied to the sample template of a MALDI-MS (Voyager Elite; Perseptive), as described recently (Jungblut et al., 1999). Peptide mass fingerprints were searched using the program MS-FIT (http://prospector.ucsf.edu/ucsfhtml/msfit.htm), reducing the proteins of the $\mathrm{NCBI}$ database to the $H$. pylori proteins and to a molecular mass range estimated from 2$\mathrm{DE} \pm 20 \%$, allowing a mass accuracy of $0.1 \mathrm{Da}$ for the peptide mass.

\section{Laser scanning confocal immunofluorescence (IF) microscopy}

To localize CagA proteins directly during infection, AGS cells were exposed to $H$. pylori wild types, vir and cagA mutant strains. Monolayers of $2 \times 10^{4}$ AGS cells were grown overnight in 16-well Lab-Tek chambers (Nunc) and infected with $\mathrm{H}$. pylori cells of the indicated strains at an MOI of 50 . Three hours after infection, the cells were washed with PBS to remove non-adherent bacteria and fixed with $4 \%$ formaldehyde in PBS. The cultures were permeabilized with $0.1 \%$ Triton $X-100$ in PBS for 30 min and stained with antibodies against $H$. pylori [rabbit serum 1:100 (Dako)/antirabbit IgG-Alexa 594 (Molecular Probes)], CagA (mouse serum 1:200, anti-mouse IgG-Cy5; Jackson), and filamentous actin was visualized using phalloidin-AlexaFluor 488 (Molecular Probes). Specimens were analysed with a confocal microscope (Leica TCS-SP).

\section{Acknowledgements}

We are grateful to P. R. Suryanarayanan and Corinna Kik for help in cloning experiments, and Terry Kwok, Stefan Moese and Efterpi Kardalinou for critical discussion of the data. We are also grateful to Stephanie Lamer for help with the MALDI-MS, and Jani O'Rourke (University of New South Wales, School of Microbiology and Immunology, Sydney, Australia), Jetta Bijlsma, Hans Kusters (Department of Medical Microbiology, Vrieje Universiteit Amsterdam, The Netherlands) and Galip Karaali for providing $H$. pylori strains SS1, 1061 and P210 respectively. This work was supported by grants from the Fonds der Chemischen Industrie to T.F.M. and M.N.

\section{References}

Aihara, M., Tsuchimoto, D., Takizawa, H., Azuma, A., Wakebe, H., Ohmoto, Y., et al. (1997) Mechanisms involved in
Helicobacter pylori-induced interleukin-8 production by a gastric cancer cell line, MKN45. Infect Immun 65: 3218-3224.

Akopyants, N.S., Clifton, S.W., Kersulyte, D., Crabtree, J.E., Youree, B.E., Reece, C.A., et al. (1998) Analyses of the cag pathogenicity island of Helicobacter pylori. Mol Microbiol 28: 37-53.

Alm, R.A., Ling, L.S., Moir, D.T., King, B.L., Brown, E.D., Doig, P.C., et al. (1999) Genomic sequence comparison of two unrelated isolates of the human gastric pathogen Helicobacter pylori. Nature 397: 176-180 [published erratum in Nature 397: 719].

Andersson, S.G., Zomorodipour, A., Andersson, J.O., SicheritzPonten, T., Alsmark, U.C., Podowski, R.M., et al. (1998) The genome sequence of Rickettsia prowazekii and the origin of mitochondria. Nature 396: 133-140.

Backert, S., Von Nickisch-Rosenegk, E., and Meyer, T.F. (1998) Potential role of two Helicobacter pylori relaxases in DNA transfer? Mol Microbiol 30: 673-674.

Censini, S., Lange, C., Xiang, Z., Crabtree, J.E., Ghiara, P., Borodovsky, M., et al. (1996) cag, a pathogenicity island of Helicobacter pylori, encodes type I-specific and diseaseassociated virulence factors. Proc Natl Acad Sci USA 93: 14648-14653.

Christie, P.J. (1997) Agrobacterium tumefaciens T-complex transport apparatus: a paradigm for a new family of multifunctional transporters in eubacteria. $J$ Bacteriol 179: 30853094.

Corthesy-Theulaz, I., Porta, N., Pringault, E., Racine, L., Bogdanova, A., Kraehenbuhl, J.P., et al. (1996) Adhesion of Helicobacter pylori to polarized T84 human intestinal cell monolayers is pH dependent. Infect Immun 64: 3827-3832.

Covacci, A., Telford, J.L., del Giudice, G., Parsonnet, J., and Rappuoli, R. (1999) Helicobacter pylori virulence and genetic geography. Science 21: 1328-1333.

Cover, T.L., and Blaser, M.J. (1999) Helicobacter pylori factors associated with disease. Gastroenterology 117: 257-261.

Gomez-Duarte, O.G., Lucas, B., Yan, Z.X., Panthel, K., Haas, R., and Meyer, T.F. (1998) Protection of mice against gastric colonization by Helicobacter pylori by single oral dose immunization with attenuated Salmonella typhimurium producing urease subunits A and B. Vaccine 16: 460-471.

Guruge, J.L., Falk, P.G., Lorenz, R.G., Dans, M., Wirth, H.P., Blaser, M.J., et al. (1998) Epithelial attachment alters the outcome of Helicobacter pylori infection. Proc Natl Acad Sci USA 95: 3925-3930.

Haas, R., Meyer, T.F., and van Putten, J.P. (1993) Aflagellated mutants of Helicobacter pylori generated by genetic transformation of naturally competent strains using transposon shuttle mutagenesis. Mol Microbiol 8: 753-760.

Jungblut, P.R., and Seifert, R. (1990) Analysis by high-resolution two-dimensional electrophoresis of differentiation-dependent alterations in cytosolic protein pattern of HL-60 leukemic cells. $J$ Biochem Biophys Methods 21: 47-58.

Jungblut, P.R., Schaible, U.E., Mollenkopf, H.J., Zimny-Arndt, U., Raupach, B., Mattow, J., et al. (1999) Comparative proteome analysis of Mycobacterium tuberculosis and Mycobacterium bovis BCG strains: towards functional genomics of microbial pathogens. Mol Microbiol 33: 1103-1117.

Keates, S., Hitti, Y.S., Upton, M., and Kelly, C.P. (1997) Helicobacter pylori infection activates NF-kappa B in gastric epithelial cells. Gastroenterology 113: 1099-1109.

Kenny, B., DeVinney, R., Stein, M., Reinscheid, D.J., Frey, E.A., and Finlay, B.B. (1997) Enteropathogenic E. coli (EPEC) 
transfers its receptor for intimate adherence into mammalian cells. Cell 91: 511-520.

Krause, S., Bárcena, M., Pansegrau, W., Lurz, R., Carazo, J.M., and Lanka, E. (2000) Sequence related protein export NTPases encoded by the conjugative transfer region of RP4 and by the cag pathogenicity island of Helicobacter pylori share similar hexameric ring structures. Proc Natl Acad Sci USA 97: 3067-3072.

Lee, A., O'Rourke, J., De Ungria, M.C., Robertson, B., Daskalopoulos, G., and Dixon, M.F. (1997) A standardized mouse model of Helicobacter pylori infection: introducing the Sydney strain. Gastroenterology 112: 1386-1397.

Li, S.D., Kersulyte, D., Lindley, I.J., Neelam, B., Berg, D.E., and Crabtree, J.E. (1999) Multiple genes in the left half of the cag pathogenicity island of Helicobacter pylori are required for tyrosine kinase-dependent transcription of interleukin-8 in gastric epithelial cells. Infect Immun 67: 3893-3899.

Münzenmaier, A., Lange, C., Glocker, E., Covacci, A., Moran, A., Bereswill, S., et al. (1997) A secreted/shed product of Helicobacter pylori activates transcription factor nuclear factor-kappa B. J Immunol 159: 6140-6147.

Naumann, M., Wessler, S., Bartsch, C., Wieland, B., Covacci, A., Haas, R., et al. (1999) Activation of activator protein 1 and stress response kinases in epithelial cells colonized by Helicobacter pylori encoding the cag pathogenicity island. $J$ Biol Chem 274: 31655-31662.

O'Callaghan, D., Cazevieille, C., Allardet-Servent, A., Boschiroli, M.L., Bourg, G., Foulongne, V., et al. (1999) A homologue of the Agrobacterium tumefaciens VirB and Bordetella pertussis Ptl type IV secretion systems is essential for intracellular survival of Brucella suis. Mol Microbiol 33: 1210-1220.

Otto, A., Thiede, B., Müller, E.-C., Scheler, C., Wittmann-Liebold, B., and Jungblut, P. (1996) Identification of human myocardial proteins separated by two-dimensional electrophoresis using an effective sample preparation for mass spectrometry. Electrophoresis 17: 1643-1650.

Pansegrau, W., and Lanka, E. (1996) Enzymology of DNA transfer by conjugative mechanisms. Prog Nucleic Acid Res Mol Biol 54: 197-251.

Schmitt, W., and Haas, R. (1994) Genetic analysis of the Helicobacter pylori vacuolating cytotoxin: structural similarities with the IgA protease type of exported protein. Mol Microbiol 12: 307-319.

Segal, E.D., Falkow, S., and Tompkins, L.S. (1996) Helicobacter pylori attachment to gastric cells induces cytoskeletal rearrangements and tyrosine phosphorylation of host cell proteins. Proc Natl Acad Sci USA 93: 1259-1264.

Segal, E.D., Lange, C., Covacci, A., Tompkins, L.S., and Falkow, S. (1997) Induction of host signal transduction pathways by Helicobacter pylori. Proc Natl Acad Sci USA 94: 7595-7599.

Segal, E.D., Cha, J., Lo, J., Falkow, S., and Tompkins, L.S. (1999) Altered states: involvement of phosphorylated CagA in the induction of host cellular growth changes by Helicobacter pylori. Proc Natl Acad Sci USA 96: 14559-14564.

Sharma, S.A., Tummuru, M.K., Blaser, M.J., and Kerr, L.D. (1998) Activation of IL-8 gene expression by Helicobacter pylori is regulated by transcription factor nuclear factor-kappa $B$ in gastric epithelial cells. J Immunol 160: 2401-2407.

Su, B., Johansson, S., Fallman, M., Patarroyo, M., Granstrom, M., and Normark, S. (1999) Signal transduction-mediated adherence and entry of Helicobacter pylori into cultured cells. Gastroenterology 117: 595-604.

Taylor, D.E. (1999) Helicobacter pylori and its genome: lessons from the treasure map. Can J Gastroenterol 13: 218-223.

Tomb, J.F., White, O., Kerlavage, A.R., Clayton, R.A., Sutton, G.G., Fleischmann, R.D., et al. (1997) The complete genome sequence of the gastric pathogen Helicobacter pylori. Nature 388: 539-547 [published erratum in Nature 389: 412].

Tummuru, M.K., Cover, T.L., and Blaser, M.J. (1993) Cloning and expression of a high-molecular-mass major antigen of Helicobacter pylori: evidence of linkage to cytotoxin production. Infect Immun 61: 1799-1809.

Tummuru, M.K., Sharma, S.A., and Blaser, M.J. (1995) Helicobacter pylori picB, a homologue of the Bordetella pertussis toxin secretion protein, is required for induction of IL-8 in gastric epithelial cells. Mol Microbiol 18: 867-876.

Vogel, J.P., and Isberg, R.R. (1999) Cell biology of Legionella pneumophila. Curr Opin Microbiol 2: 30-34.

Winans, S.C., Burns, D.L., and Christie, P.J. (1996) Adaptation of a conjugal transfer system for the export of pathogenic macromolecules. Trends Microbiol 4: 64-68. 